\title{
Avaliação preliminar dos conhecimentos etnoclimático e etnogeomorfológico de pescadores do litoral do Município de Goiana - estado de Pernambuco / Brasil
}

\author{
Preliminary evaluation of the ethnoclimatic and \\ ethnogeomorphologic knowledge of fishermen of the coast of \\ the Municipality of Goiana - state of Pernambuco / Brazil
}

\author{
Roberta Kelly Fernandes-da-Silva ${ }^{1}$ \\ Vanessa Martins-Lopes ${ }^{2}$ \\ Osvaldo Girão ${ }^{3}$
}

Universidade Federal de Pernambuco, Brasil.

http://dx.doi.org/10.15359/rgac.60-1.11

\begin{abstract}
RESUMO
Buscou-se identificar, de forma preliminar, os saberes etnoclimáticos e etnogeomorfológicos detrês comunidades de pescadores localizadas no município de Goiana, estado de Pernambuco, objetivando identificar como os pescadores entendem os saberes relativos à sazonalidade climática e às formas e funções dos relevos costeiros, assim como classificam o ambiente físico/natural em que vivem. Foram realizados levantamentos bibliográficos e visitas às comunidades pesquisadas para reconhecimento do ambiente físico/natural onde, posteriormente, foram realizadas entrevistas de caráter qualitativo. Compreender a importância do etnoconhecimento e das experiências que os moradores das comunidades possuem em relação à dinâmica existente no meio em que praticam

1 Graduanda do Curso de Licenciatura em Geografia da Universidade Federal de Pernambuco - Brasil. robertakellype@hotmail.com

2 Mestre em Geografia pela Universidade Federal de Pernambuco - Brasil. wan.martins19@gmail.com

3 Professor Associado 1 do Departamento de Ciências Geográficas da Universidade Federal de Pernambuco

- Brasil. osgirao@gmail.com
\end{abstract}

Fecha de recepción: 07 de marzo de 2017

Fecha de aceptación: 16 de octubre de 2017 
Roberta Kelly Fernandes-da-Silva, Vanessa Martins-Lopes, Osvaldo Girão. Preliminary evaluation of the ethnoclimatic and ethnogeomorphologic knowledge of fishermen of the coast of the Municipality of Goiana state of Pernambuco / Brazil

a pesca, poderá contribuir de forma eficaz em ações desenvolvidas pelo poder público a partir da participação dos moradores locais com seus conhecimentos, experiências e práticas.

Palavras-chave: Etnoconhecimento; Comunidades pesqueiras; Geomorfologia Costeira; Litoral Norte de Pernambuco; Goiana-PE.

\begin{abstract}
This study aimed at preliminarily finding the ethnoclimatic and ethno-geomorphological knowledge of three fishing communities located on the municipality of Goiana, in the state of Pernambuco. This aimed at identifying how fishermen understand the knowledge about the climatic seasonality and the forms and functions of the coastal reliefs, as well as classifying the physical / natural environment in which they live. Bibliographical surveys were carried out and visits to the surveyed communities were made to recognize the physical/natural environment where qualitative interviews were subsequently conducted. Understanding the importance of ethno-knowledge and the experiences that the residents of the communities have in relation to the dynamics existing in the environment in which they practice fishing, may contribute effectively to actions developed by the public power from the participation of residents with their knowledge, experience and practices.
\end{abstract}

Keywords: Ethno-knowledge; Fishing communities; Coastal Geomorphology; North Coast of Pernambuco; Goiana-PE.

\title{
Introdução
}

As comunidades tradicionais, como a de pescadores artesanais, que conhecem intimamente o ambiente costeiro através da vivencia com o lugar, detém práticas de uso e manejo que não causam grandes impactos ao ambiente natural,se comparadas às práticas da sociedade urbano-industrial. A terra, a água, a fauna, a flora e outros elementos da natureza são partes integrantes de suas rotinas diárias, e geralmente dos quais dependem a sua sobrevivência, por isso são tratados com um elo de afetividade, o que implica em um maior grau de comprometimento com a conservação da dinâmica do sistema natural.

Em tais ambientes a diversidade ecológica, em muitos casos, é mantida a partir da diversidade cultural e das técnicas existentes nas comunidades de jangadeiros e caiçaras, aspectos majoritariamente desconsiderados em políticas voltadas para a proteção ambiental, que poderiam considerar estratégias de sobrevivência das culturas locais e os modos de vida das populações litorâneas, que consideram a necessidade da manutenção de um equilíbrio ambiental.

Dentro da perspectiva apresentada, o estudo realizado justificou-se pela necessidade do reconhecimento da construção e manutenção dos conhecimentos tradicionais sobre o relevo costeiro de comunidades de 
Roberta Kelly Fernandes-da-Silva, Vanessa Martins-Lopes, Osvaldo Girão. Avaliação preliminar dos conhecimentos etnoclimático e etnogeomorfológico de pescadores do litoral do Município de Goiana - estado de Pernambuco / Brasil

pescadores artesanais no município de Goiana, localizado no litoral norte do estado de Pernambuco, como estudo voltado para futuras ações deplanejamento e gestão territorial e de conservação ambiental costeira, uma vez que o município em questão abriga varias comunidades de pescadores que se dedicam ao sistema artesanal de pesca, mas que recentemente veem sofrendo pressões ambientais decorrentes da expansiva atividade imobiliária sobre a orla costeira municipal.

As possíveis aplicações do estudo realizado visam mitigar problemáticas relativas à ações voltadas para o planejamento e gestão ambiental e territorial, que desconsideram o conhecimento dos moradores sobre a realidade ambiental e cultural em suas aplicações, sendo tais considerações essenciais para proposições racionais junto aos moradores envolvidos, que habitam e, majoritariamente, praticam atividades econômicas relacionadas com o ambiente costeiro, considerado de equilíbrio frágil e dinâmico.

A compreensão do conhecimento tradicional sobre as dinâmicas ambientais naturais, a nível climático e geomorfológico, devem ser considerados em ações públicas pois potencializam o sucesso das mesmas ao envolver populações locais com contribuições valorosas sobre modificações sazonais, anuais ou mesmo decanas quanto ao comportamento climático e suas repercussões sobre processos e formas geomorfológicas presentes em ambientes costeiros.

Desta forma, foi objetivo geral do estudo é identificar como as comunidades de pescadores artesanais das comunidades de Atapuz, Barra de Catuama e Carne de Vaca entendem as dinâmicas climáticas e suas repercussões sobre os processos e as formas geomorfológicas, assim como denominam, classificam e manejam o ambiente físico/natural costeiro em que vivem, enfatizando, dentre as características geoambientais, aquelas de caráter geomorfológico, sendo objetivos específicos identificar qual a percepção etnoecológica que as comunidades de pescadores artesanais possuem sobre o ambiente em que vivem, e classificar, etnogeomorfologicamente, o relevo local a partir do etnoconhecimento coletado em campo, assim como identificar uma correlação entre os conhecimentos geomorfológicos acadêmicos e etnogeomorfológicos locais. 
Roberta Kelly Fernandes-da-Silva, Vanessa Martins-Lopes, Osvaldo Girão. Preliminary evaluation of the ethnoclimatic and ethnogeomorphologic knowledge of fishermen of the coast of the Municipality of Goiana state of Pernambuco / Brazil

\section{Área de estudo}

As comunidades pesqueiras estão localizadas em ambiente costeiro-estuarino, sendo uma no litoral norte, Carne de Vaca, na desembocadura do rio Megaó, e duas no litoral sul, Barra de Catuama e Atapuz, na entrada norte do canal de Santa Cruz, todas no município de Goiana, ao norte do estado de Pernambuco (figuras 1).As três comunidades avaliadas possuem como bases da economia a prática da pesca, assim como a atividade turística de lazer.

Na costa Nordeste Oriental, na qual localiza-se o estado de Pernambuco, predomina planícies costeiras, praias e franjas de recifes de arenitos de praias, além de falésias pontuais a retaguarda de algumas praias. As lagunas e estuários também são ocupados por manguezais, e nessa área há grande influência dos ventos de sudeste. Em termos geológicos o litoral norte pernambucano pertence ao domínio estrutural da Bacia Sedimentar Paraíba.

A faixa costeira de Goiana é litologicamente diversificada, sendo composta pelos depósitos Cretáceos-paleocênicos do Grupo Paraíba, depósitos Plio-pleistocênicos da Formação Barreiras e depósitos quaternários. Essa litologia exerce importante papel na gênese geomorfológica da área em questão, dividindo-a em três unidades geomorfológicas: Tabuleiros Costeiros, Domínio Colinoso e Planícies Costeiras (CPRH, 2003).

As planícies costeiras, ou litorâneas,unidade onde está inserida a área objeto do estudo, são planícies formadas por sedimentos terciários ou quaternários, depositados na zona costeira. A gênese desse ambiente está relacionada a vários fatores, como as variações do nível do mar do quaternário associadas às correntes de deriva litorânea, às fontes primárias de sedimento e às "armadilhas" para retenção do sedimento. Freqüentemente essas planícies estão associadas a desembocaduras de grandes rios e/ou reentrâncias na linha de costa. Segundo Silva (2012) essa é uma unidade geológico-geomorfológica de grande complexidade, já que se trata de um ambiente de transição entre fenômenos continentais e marinhos, onde ocorrem diversos tipos de ambientes geomorfológicos.

Quanto à dinâmica climática local, cinco sistemas atmosféricos atuantes são responsáveis pelas precipitações no Litoral Norte de Pernambuco, de acordo com Oliveira (2003),são: 
Roberta Kelly Fernandes-da-Silva, Vanessa Martins-Lopes, Osvaldo Girão. Avaliação preliminar dos conhecimentos etnoclimático e etnogeomorfológico de pescadores do litoral do Município de Goiana - estado de Pernambuco / Brasil

- Vórtices Ciclônicos da Atmosfera Superior (VCAS), atuantes a partir do fim da primavera a início do verão (novembro a janeiro);

- Brisas marítimas, atuantes ao longo do ano, com maior intensidade no outono-inverno (março a setembro);

- Zona de Convergência Intertropical (ZCIT), atuantes durante o verão-outono (dezembro a junho);

- Frentes frias, atuantes durante o outono-inverno (março a setembro);

- Sistemas ondulatórios de leste, atuantes durante o outono-inverno (março a setembro);

Para o litoral de Goiana, há um gradativo aumento de precipitação a partir de fevereiro, com valores médios mensais variando entre 50 à 100 $\mathrm{mm}$, março e abril com valores superiores à $200 \mathrm{~mm}$, atingindo a precipitação máxima, superior à $300 \mathrm{~mm}$, no mês de junho. A intensidade de chuvas nessa região, durante esta época do ano, está diretamente relacionada à posição e intensidade da alta pressão do Atlântico Sul e à temperatura do Atlântico Sul, próximo à costa brasileira. A partir de julho, final da estação chuvosa da região, as precipitações tendem a diminuir, atingindo valores em torno de $50 \mathrm{~mm}$ no mês de setembro (Manso et.al., 2006).

Ainda segundo Manso et.al. (2006), durante o inverno, predominam os ventos de sudeste, com velocidades médias entre 5,0 a $6,1 \mathrm{~m} / \mathrm{s}$, já no verão, predominam os ventos de nordeste, com velocidade média de $5,2 \mathrm{~m} / \mathrm{s}$. Os ventos alísios de sudeste e as brisas marinhas exercem grande influência nas condições climáticas da área, ora minimizando, ora maximizando os efeitos térmicos advindos da insolação. 
Roberta Kelly Fernandes-da-Silva, Vanessa Martins-Lopes, Osvaldo Girão. Preliminary evaluation of the ethnoclimatic and ethnogeomorphologic knowledge of fishermen of the coast of the Municipality of Goiana state of Pernambuco / Brazil

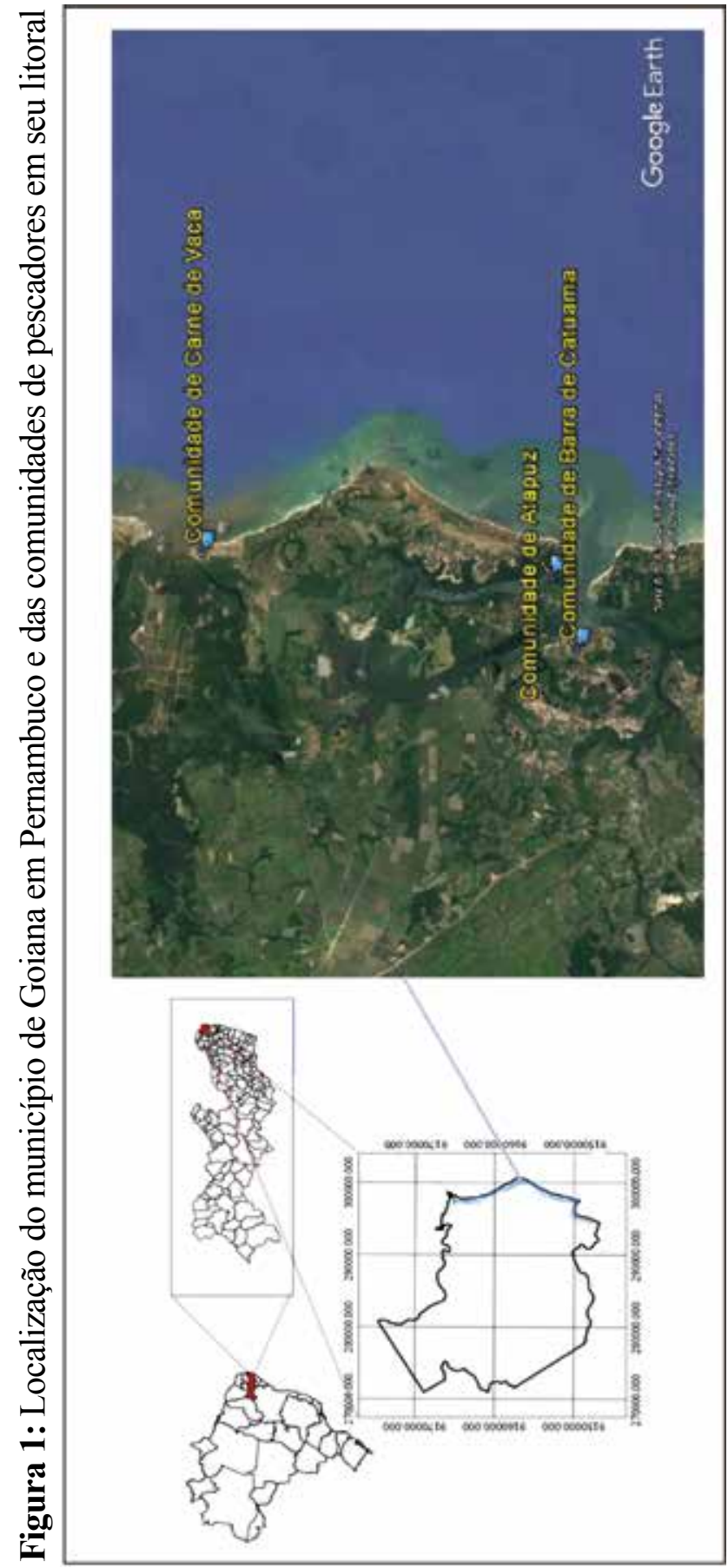


Roberta Kelly Fernandes-da-Silva, Vanessa Martins-Lopes, Osvaldo Girão. Avaliação preliminar dos conhecimentos etnoclimático e etnogeomorfológico de pescadores do litoral do Município de Goiana - estado de Pernambuco / Brasil

\section{Marco teórico-conceitual}

Os conhecimentos tradicionais adquiridos pelos pescadores, diferentemente do conhecimento científico, devem ser levados em consideração, baseados no fator de pertencimento e experiência, de fazer parte da dinâmica socioambiental local. Ou seja, é reconhecer a existência de várias experiências e saberes, os quais os indivíduos praticam no seu dia a dia.

Assim, oetnoconhecimento das comunidades tradicionais expressa de forma única como conviver com a natureza, seus limites e sua dinâmica, pois:

O prefixo etno faz referência aos aspectos e conhecimentos específicos de povos ou etnias, ou seja, aos conhecimentos de grupos de indivíduos que compartilham uma cultura. Assim, os estudos etnocientíficos são aqueles que procuram compreender como comunidades com cultura própria se inter-relacionam com plantas, animais e com o próprio lugar ou território em que se encontram, ou seja, os conceitos e saberes desenvolvidos por uma cultura sobre diferentes áreas do conhecimento nas relações povosnatureza. Estes saberes advêm de gerações de experimentações entre estas sociedades e seu meio ambiente buscando melhores formas de uso e manejo dos recursos naturais através do tempo, e tem como característica fundamental a interdisciplinaridade das ações e a busca do reconhecimento do valor intelectual deste etnoconhecimento (Ribeiro, 2012).

De acordo com suas necessidades, os pescadores percebem, concebem e conceituam os ambientes e suas formas, criando técnicas para alcançar seus objetivossócioeconômicos, ou seja, conseguir sua sustentabilidade econômica, mas também do ponto de vista físico-ambiental.

$O$ grau de enraizamento das pessoas com o meio ambiente em que vivem faz com que elas construam vínculos e identidades únicas, enriquecendo suas tradições, conhecimentos e culturas. $\mathrm{O}$ ser humano se apropria da natureza de acordo com sua cultura, com o seu território étnico, uma vez que:

O homem é o resultado do meio cultural em que foi socializado. Ele é um herdeiro de um longo processo acumulativo, que reflete o conhecimento e a experiência adquiridas pelas numerosas gerações que o antecederam (Laraia, 2009, p.45 apud CArvalho Neta, Ribeiro, MarcaL e Lima, 2014). 
Roberta Kelly Fernandes-da-Silva, Vanessa Martins-Lopes, Osvaldo Girão. Preliminary evaluation of the ethnoclimatic and ethnogeomorphologic knowledge of fishermen of the coast of the Municipality of Goiana state of Pernambuco / Brazil

No caso de comunidades de pescadores, a partir dos vínculos criados com o meio, a percepção de qualquer mudança da dinâmica do ambiente em que vivem é de extrema importância para a busca de um reequilíbrio ambiental. Para tanto, a conservação e continuação de práticas tradicionais de pesca auxiliam os pescadores perceberem que há processos de mudanças, e que estas tentam identificar as causas com suas experiências, e alteram, se necessário, práticas ou mesmo locais de pesca, a exemplo da noção/percepção de que o "clima está mudando" e afetando a atividade pesqueira, na quantidade e qualidade dos pescados.

Neste contexto, no âmbito do conhecimento de comunidades locais, ou do etnoconhecimento, tanto a etnoclimatologia quanto a etnogeomorfologia podem ser consideradas como uma abordagem etnoecológica, uma ciência híbrida estruturada a partir da combinação de ciências naturais e sociais (Ribeiro, 2012), que busca a integração de conhecimentos locais aos considerados acadêmicos.

A Etnoclimatologia, segundo Nasuti et al. (2013), pode ser definida como uma análise da relação e interação entre os fatores e elementos climáticos e as culturas humanas, que utilizam o conhecimento adquirido sobre o clima local a partir de suas observações e conhecimentos empíricos sobre o meio natural (Gascón, 2014, GAscón e Caviedes, 2014).

Os estudos de caráter etnoclimáticos implicam o conhecimento empírico do tempo atmosférico e dos tipos climáticos e mesmos de suas dinâmicas sazonais em um determinado local, produto do contato, observação e interação com o meio, sendo estes aperfeiçoados ao longo do tempo por sucessivas gerações, que resguardam e os transmitem, sendo seus fundamentos baseados em saberes tradicionais, transmitidos mediante narrativas orais.

São várias as razões para a valorização dos conhecimentos etnoclimáticos, que no Brasil, estão embrionariamente voltados para o semiárido do nordeste do país (Folhes e Donald, 2007; Medeiros, Pinto e Rozendo, 2014), mas entre elas é pertinente destacar seu valor como acervo cultural e memória popular, e as valiosas informações que o conhecimento das dinâmicas climáticas de um passado recente podem ser confrontadas com dinâmicas presentes à escala de detalhe local (Fuentes, Bastos e Santos, 2015).

Quanto à etnogeomorfológica, esta visa resgatar os valores das culturas locais sobre suas interpretações sobre o relevo, pautando-se sob a ótica do entendimento e práticas de uso e manejo que essas comunidades 
Roberta Kelly Fernandes-da-Silva, Vanessa Martins-Lopes, Osvaldo Girão. Avaliação preliminar dos conhecimentos etnoclimático e etnogeomorfológico de pescadores do litoral do Município de Goiana - estado de Pernambuco / Brasil

exercem sobre a paisagem geomorfológica de que fazem parte, dando ênfase as formas e processos morfogenéticos e morfodinâmicos atuantes em determinadas localidades (RIBEIRO, 2012). Desta feita, as taxonomias e classificações locais para as formas e processos geomorfológicos são igualmente relevantes para a obtenção de uma visão ampla sobre a relação entre grupos sociais e o meio natural em estudos etnogeomorfológicos.

Os estudos etnogeomorfológicos podem, ainda, contribuir para um "desenvolvimento local" a partir de um "envolvimento local" das comunidades tradicionais, contribuindo para ações de geoconservação ambiental a partir do manejo e gestão socioambiental desses grupos no local em que vivem, tendo, a partir da valorização de seus conhecimentos, o poder de atuar nas intervenções governamentais, e mesmo privadas, sobre seus locus habitacionais.

Além das contribuições as formas de usos e ocupações a partir da dinâmica das zonas costeiras, deve-se considera estas como áreas extremamente frágeis no que se refere à degradação de seus recursos pela ocupação antrópica, além de serem geomorfologicamente instáveis a inputs climáticos e oceanográficos (Cabral, Silva e Girão, 2014).

Essa instabilidade em ambientes costeiros decorre das alterações por efeitos naturais e antrópicos, que se revelam em modificações na disponibilidade de sedimentos, no clima de ondas e na altura do nível relativo do mar. A variação no nível do mar é um dos principais mecanismos responsáveis por modificações na linha de costa e da configuração litorânea (Muehe, 1994), sendo um dos principais reflexos de mudanças morfodinâmicas percebidas por pescadores.

Sendo um ambiente instável, possíveis fragilidades requerem formas de planejamento e gerenciamento costeiro para manter o equilíbrio e conservação dessas áreas, que não exigem, exclusivamente, como nos vem à primeira instância, a utilização de técnicas e recursos tecnológicos, apenas, pois são nas práticas vistas, geralmente, como rudimentares, que pode está à "chave" da manutenção da dinâmica natural e conservação ambiental, e é neste contexto que os povos tradicionais litorâneos exercem papel relevante na possibilidade de contribuir de forma efetiva para implementação de ações de manutenção e/ou reequilíbrio ambiental visando ações de planejamento e gestão territorial 
Roberta Kelly Fernandes-da-Silva, Vanessa Martins-Lopes, Osvaldo Girão. Preliminary evaluation of the ethnoclimatic and ethnogeomorphologic knowledge of fishermen of the coast of the Municipality of Goiana state of Pernambuco / Brazil

\section{Marco teórico-metodológico}

O presente trabalho possui como base os aportes teórico-metodológicos de Ribeiro (2012), a qual propõe o estudo geomorfológico sob um novo olhar, pautado na perspectiva etnocientífica. A autora buscou a compreensão acerca das formas de relevo e processos morfoesculturadores a partir do conhecimento local de comunidades tradicionais.

Uma categoria de análise geográfica atrelada a essa investigação é a de paisagem, sustentada na perspectiva geossistêmica de Sotchava (1977), como um conjunto de elementos integrados e indissociáveis em constante evolução. No entanto, procurou-se trabalhar este conceito em uma perspectiva cultural, buscando inserir os valores das culturas locais com suas visões de mundo, organização de conhecimentos e classificações ambientais, tendo como ênfase os conhecimentos etnogeomorfológicos.

A escolha das comunidades de comunidades de Atapuz, Barra de Catuama e Carne de Vaca foi realizada baseada em suas localizações na área costeira, ou seja, ambientes que se constituem em zonas de contato entre terra, mar e dinâmica climática com ecossistemas diferentes, incluindo os manguezais. Ademais, foi considerada a base econômica das comunidades voltada para a atuação pesqueira, que muitas vezes é praticada de forma precária pelos pescadores, onde os mesmos buscam formas diversas para adaptar o seu trabalho à dinâmica natural desses ambientes aquáticos.

Pós a escolha das áreas de pesquisa foi realizada a primeira atividade de campo no dia 11 de dezembro de 2015, nos locais escolhidos em cada comunidade para reconhecimento do ambiente físico/natural, onde, posteriormente, seriam realizadas as entrevistas.

O retorno a campo ocorreu na data de dia $1^{\circ}$ de abril de 2016 para aprofundamentos dos dados levantados na primeira ida a campo e para a elaboração do roteiro de entrevista de caráter qualitativo, com questões que objetivaram identificar etnoconhecimentos tradicionais das comunidades de pescadores relacionados com formas e processos geomorfológicos costeiros.

Os momentos voltados para as entrevistas foram os períodos de 27 a 29 de junho e $1^{\circ}$ de julho de 2016, objetivando identificar e analisar os conhecimentos dos(as) pescadores(as) sobre as formas e funções do relevo e como eles classificam e manejam o ambiente físico/natural em que vivem, 
Roberta Kelly Fernandes-da-Silva, Vanessa Martins-Lopes, Osvaldo Girão. Avaliação preliminar dos conhecimentos etnoclimático e etnogeomorfológico de pescadores do litoral do Município de Goiana - estado de Pernambuco / Brasil

quando foram aplicadas 15 entrevistas, sendo cinco para cada comunidade, com questões referentes aos seguintes tópicos:

- $\quad$ Percepção de mudanças no nível relativo do mar e mudanças na paisagem;

- Percepção de influências naturais e sazonalidade sobre a atividade pesqueira;

- Dinâmica hidrológica e processos modeladores da paisagem geomorfológica;

- As formas geomorfológicas.

As entrevistas foram gravadas em áudio e depois transcritas, o que possibilitou analisar e compreender de forma mais minuciosa os dados coletados em campo e como os pescadores entendem as formas e funções do relevo, como classificam e manejam o ambiente costeiro em que vivem.

Por fim, em compilações e análises de gabinete, foram correlacionados os etnoconhecimentos sobre o relevo costeiro com a geomorfologia costeira acadêmica, buscando similaridades entre os conceitos das duas "comunidades".

\section{Resultados}

Nas atividades de campo foi aventado de forma recorrente pelos pescadores que o ambiente costeiro vem sofrendo degradação em decorrência do aparecimento de pontos de erosão marinha, segundo eles por questões naturais, influenciadas pelas mudanças climáticas, mais também antrópicas, como construções irregulares que avançam sobre áreas de influências das marés. Acerca de mudanças perceptíveis em áreas costeiras por moradores devido a mudanças nas formas de usos ocupacionais, tem-se que:

A percepção de que o litoral é um ambiente sujeito a mudanças se estabelece à medida que aumenta a ocupação da orla costeira de modo que efeitos erosivos que antes da ocupação eram ignorados por não causarem prejuízos, passam a ser vistos como fator de risco, implicando em questões econômicas e sociais (MUEHE, 2006).

A cada relato dos pescadores entrevistados, percebia-se a importância e a validade dos conhecimentos e experiências que os mesmos possuem 
Roberta Kelly Fernandes-da-Silva, Vanessa Martins-Lopes, Osvaldo Girão. Preliminary evaluation of the ethnoclimatic and ethnogeomorphologic knowledge of fishermen of the coast of the Municipality of Goiana state of Pernambuco / Brazil

acerca do ambiente em vivem, e que estes se firmamem suas práticas sociais e labutais, mas também em relação aos limites e mudanças do meio ambiente, levando-os a"se aproximar" de conhecimentos usados no meio científico visando necessidades, conforme atestam Lopes e Pereira (2014, p.3171 apud Toledo e Barrera-Bassols, 2009):

O conhecimento das populações tradicionais é holístico, porque resulta das necessidades de uso e manejo dos recursos naturais, dessa forma elas detém um detalhado catálogo de conhecimento acerca da estrutura, elementos, processos, dinâmicas e potenciais da natureza. Assim os indivíduos reconhecem informações sobre espécies de plantas, animais, fungos, e alguns microorganismos, além de diversos tipos de minerais, solos, água, neve, vegetação e paisagens.

Informações e percepções de pescadores e pescadoras relativas à mudanças no nível relativo do mar, influências de elementos naturais e da sazonalidade sobre a atividade pesqueira, dinâmica hidrológica e processos modeladores da paisagem geomorfológica, e as formas geomorfológicas identificadas foram reveladas através das entrevistas realizadas que, em síntese, apresentaram os resultados que seguem nos próximos tópicos.

\section{Percepção de mudanças no nível relativo do mar e mudanças na paisagem}

Para Davidson-Arnott (2010) não é tão simples determinar variações do nível relativo do mar ao longo do tempo, já que a história real dessas mudanças ao longo de qualquer costa específica também irá variar em razão de outros fatores tais como a elevação isostática e fatores tectônicos locais.

As mudanças nos níveis relativos do mar têm continuado a influenciar a evolução morfodinâmicadas zonas costeiras, no entanto estas também têm sido influenciadas e modificadas pelos efeitos de várias atividades antrópicas ocorridas não só ao longo da linha de costa mas também no interior do continente (Bird, 2008).

As atividades antrópicas ao longo da linha de costa ou em suas proximidades podem surgir a partir da construção de portos, ocupação indevida de setores da costa que deveriam estar protegidos e, inclusive, das próprias obras de engenharia costeira, quando mal projetadas, pois essas 
Roberta Kelly Fernandes-da-Silva, Vanessa Martins-Lopes, Osvaldo Girão. Avaliação preliminar dos conhecimentos etnoclimático e etnogeomorfológico de pescadores do litoral do Município de Goiana - estado de Pernambuco / Brasil

ações podem alterar o fluxo de sedimentos entre continente e oceano e vice-versa, além de influenciar sobre a dinâmica das ondas e marés e a orientação da deriva litorânea causando erosão da costa em determinados locais e sedimentação em outros. No interior do continente, a retirada de sedimentos dos cursos fluviais pode causar um déficit sedimentar na desembocadura do canal fluvial causando também a erosão em ambientes estuarinos ou deltaicos (Bird, 2008; Davidson-Arnott, 2010).

Em relação à variação do nível no mar, os pescadores de Goiana relataram percepções diversas, pois para 9 dos entrevistados há indícios de avanços e recuos, e outros 6 não perceberam diferenças, pois entendem que continua no mesmo nível há anos.

Os que perceberam que o mar avançou, relatam vários motivos, como: a ação dos ventos e das ondas, que fazem com que os bancos de areia "desçam" para a área costeira, não mais permitindo a presença de pescado, dificultando, assim, a presença dos mangues e cobrindo rochas, onde antes os peixes se alimentavam. Estes também relataram como causas os aterros e ocupações próximas da linha de costa, fazendo com que o mar, dentro de sua dinâmica, venha a atuar modificando o meio ambiente costeiro local, e mesmo atuando na gênese de prejuízos materiais quando atingem estruturas próximas a linha de costa (figura 2).

Outros ainda acreditam na influencia de um provável aquecimento global, e alguns que a questão é natural, relacionada com a dinâmica costeira. Muitos disseram que o relativo avanço do nível do mar influencia na atividade de pesca, diminuindo as espécies e quantidades, pois onde antes era "berçário" dos peixes virou "croa" (banco de areia). Ademais, as mudanças na dinâmica da linha de costa modificaram áreas de acesso à pesca, e mesmo destruiu algumas edificações/estruturas. 
Roberta Kelly Fernandes-da-Silva, Vanessa Martins-Lopes, Osvaldo Girão. Preliminary evaluation of the ethnoclimatic and ethnogeomorphologic knowledge of fishermen of the coast of the Municipality of Goiana state of Pernambuco / Brazil

Figura 2: Ocupação residencial de pescadores na linha de costa comunidade de Atapuz.

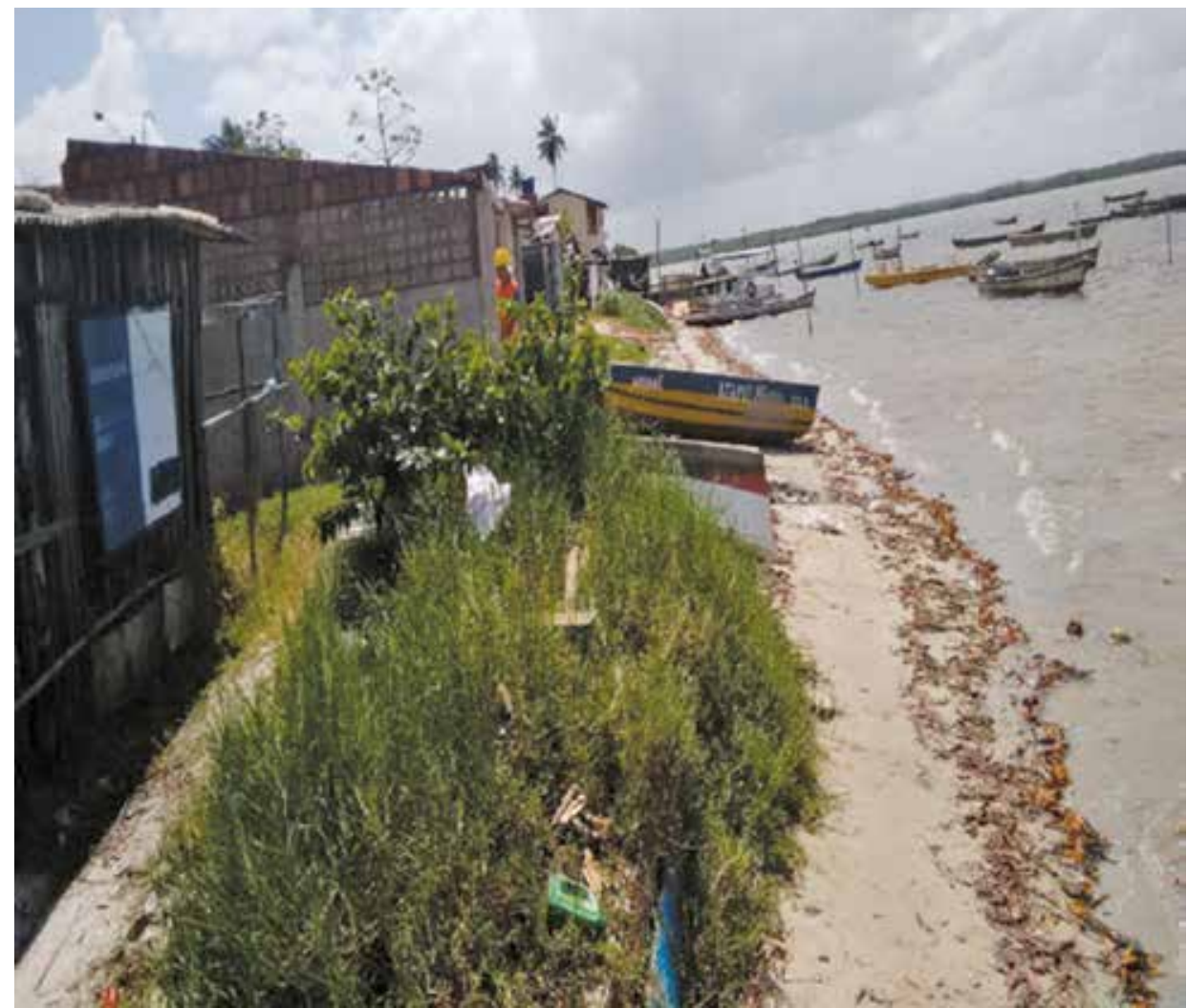

Fonte: Os autores (2016).

A partir do relato dos que acreditam que está ocorrendo modificações no nível do mar, percebe-se que estes possuem entendimento sobre variações sazonais e mesmo como formas de uso e ocupação podem influenciar sobre a percepção de variações na linha de costa.

Percepçõesda sazonalidade climática e cobertura vegetal natural sobre a atividade pesqueira

Para os 15 entrevistados há interferências das estações do ano na pesca, pois esta variana dependência da época do ano. Para muitos entrevistados, o inverno (junho a setembro) é um período ruim para a pesca porque chove recorrentemente, há um aqueda relativa de temperatura e os 
Roberta Kelly Fernandes-da-Silva, Vanessa Martins-Lopes, Osvaldo Girão. Avaliação preliminar dos conhecimentos etnoclimático e etnogeomorfológico de pescadores do litoral do Município de Goiana - estado de Pernambuco / Brasil

ventos são fortes, mas, em contrapartida, as chuvas ao escoar com carga de sedimentos para os rios "suja" a água, facilitando a pesca para alguns tipos de pescado, como a Tainha (Mugil brasiliensis) e a Carabepa (Diapterusrhombeus), porque o peixe "desce" e não vê a rede. Já para outros pescadores, o inverno é ruim porque afastam os peixes do mar que entram para o estuário superior do rio Megaó, em busca de água doce e temperaturas menores que a do mar. Para muitos, durante o verão é bom para a pesca porque o mar está mais calmo, e o vento não é muito forte.

O vento é outro fator considerado importante e de forte influência na prática da pesca considerando a sazonalidade,pois, segundo os pescadores, existem ventos de norte, nordeste, sul, sudeste, vento "terrar" ou brando, vento "de fora" ou "gerar", que vem do mar. Os ventosde sudeste e sul são considerados fortes, ocorrendo na época de invernoentre julho e setembro, sendo os chamados Alísios de Sudeste. No verão, entre dezembro e janeiro, os pescadores mencionaram o chamado vento "de fora", alusão aos Alísios de Nordeste, considerados deintensidade forte a moderado, sendo também considerado brando e bom para a atividade da pesca.

Fica evidente que os ventos Alísios de Sudeste são mais atuantes e intensos no litoral em questão no período de outono-inverno (março-setembro), enquanto Alísios de Nordeste atuam de forma amena durante a primavera-verão (setembro-março).

Quanto à pluviosidade, os períodos de maior e menor intensidade desta, localmente denominados de "inverno" e "verão", respectivamente, influenciam da dinâmica da paisagem e da atividade de pesca, segundo os pescadores, pois nos períodos de maiores precipitações, que corresponde, na verdade, ao outono-inverno (março a setembro), o peixe vai para a "cabeceira" dos rios, e é bom para a pesca de crustáceos. No entanto, grande parte dos pescadores reclama que com a chuva a água fica fria e "grossa", ou seja, fica suja, devido à carga de sedimentos lançadas dos interflúvios nos rios, e mesmo da porção emersa na linha de costa, de modo que a pescaria se torna difícil por conta da turbidez da água.

Ainda segundo os pescadores, quando a chuva cai sobre a superfície aquosa, faz barulho sobre a água e o peixe "afunda", ou seja, mergulha para as porções mais profundas. Além disso, há a influência da grande descarga de água doce sobre a salinidade local, porque quando há o lançamento de 
Roberta Kelly Fernandes-da-Silva, Vanessa Martins-Lopes, Osvaldo Girão. Preliminary evaluation of the ethnoclimatic and ethnogeomorphologic knowledge of fishermen of the coast of the Municipality of Goiana state of Pernambuco / Brazil

água nova no mar, e com a queda da salinidade, o peixe se afasta e permanece no que eles denominam de "mar de fora", distante da costa.

Deste modo, para a maioria dos pescadores, o verão é considerado a melhor época, porque a água fica mais quente e limpa, e aliada ao vento que é mais brando, promove a incidência de uma maior diversidade e quantidade de peixes que se aproximam da costa.

Quanto à vegetação natural, existente nas comunidades pesquisadas, há referênciasa diversos tipos de mangue, como: botão ou bolota ( $\mathrm{Coma-}$ carpuserectus), bravo ou gaiteiro (mangue vermelho - Rhizophoramangle) e mangue tinteiro ou manso (mangue branco - Laguncularia racemosa).

Tais vegetações são importantes para a prática da pesca, pois como relataram os pescadores, é através destas que há oxigênio, permitindo que os peixes venham desovar, e de onde eles, os pescadores, também podem aproveitar-se de recursos para sobrevivência, como na prática do extrativismo de ostras, siris, mariscos e caranguejos.

Além do extrativismo animal, há uma relativa atividade de extrativismo vegetal, apesar dos pescadores terem consciência de que é proibido retirar madeira do manguezal, mas muitos disseram que só extraem a madeira "morta" (galhos caídos) para utilizar como lenha para cozinhar os mariscos, pois o custo de cozinhar em fogão a gás é considerado alto. Outros retiram lenha para construção de telhados, e para usar na atividade de pesca, em embarcações.

\section{Processos modeladores da paisagem geomorfológica e dinâmica hidrológica}

As marés ocorrem em um ciclo diário alternante de seis em seis horas. Assim, elas passam um período de seis horas de fluxo (para alcançar a preamar), e seis horas de refluxo (para alcançar a baixa-mar), de modo que em um dia lunar $(24 \mathrm{~h} 50 \mathrm{~m} 28 \mathrm{~s})$ há duas preamares e duas baixa-mares. É justamente por causa da diferença de tempo entre o dia solar (24h) e o dia lunar que as marés possuem uma variação de aproximadamente 50 minutos de um dia para o outro (Davidson-Arnott, 2010; Lopes, 2017).

Além das variações diárias, as marés possuem variações mensais, relacionadas aos astros, como a Lua e o Sol, que irão definir os diferentes tipos de marés existentes identificados pelos pescadores, os quais são muito importantes na prática de pesca. 
As oscilações diárias das marés através do processo de fluxo e refluxo são classificadas por eles como "maré de enchente", quando o nível da maré está subindo e "maré de vazante" quando o nível esta descendo. Denominam de "maré alta" quando está em seu nível máximo, ou seja, na preamar, e "maré baixa" em seu nível mínimo, ou seja, baixa-mar, quando evidencia-se as chamadas planícies de maré com o recuo na baixa-mar (figuras 3 e 4).

Para Lopes (2017), a dinâmica das marés interfere e influencia na prática da pesca, existindo vários tipos de marés, que os pescadores nomeiam e se baseiam por elas para saber qual é a melhor maré para se pescar.

A "maré cheia", grande ou de lançamento, para uns, é bom para a pesca de rede de fundo, e para outros é ruim por conta da correnteza que a mesma promove, que é maior. A “maré de vazante", baixa, ou baixa-mar, também denominada de maré de quebramento, é quando a maré está secando que, dependendo da pesca, é melhor para se conseguir determinados recursos como o marisco.

Os pescadores denominam de "maré de fevereiro", ou de Carnaval, a maré mais alta (maré de sizígia); outra forma de maré é a de mosquito, ou maré de renovação, quando não há uma forte subida do nível, mas o suficiente para "lavar" o mangue, retirando resíduos e atraindo peixes e crustáceos, melhorando a atividade de pesca. 
Roberta Kelly Fernandes-da-Silva, Vanessa Martins-Lopes, Osvaldo Girão. Preliminary evaluation of the ethnoclimatic and ethnogeomorphologic knowledge of fishermen of the coast of the Municipality of Goiana state of Pernambuco / Brazil

Figura 3: "Maré de lançamento" quase na fase de "maré grande" na Praia Carne de Vaca. momento de refluxo dessa maré onde se pode observar a sua amplitude, tanto pela linha de preamar como pelas embarcações que na imagem aparecem sobre a areia

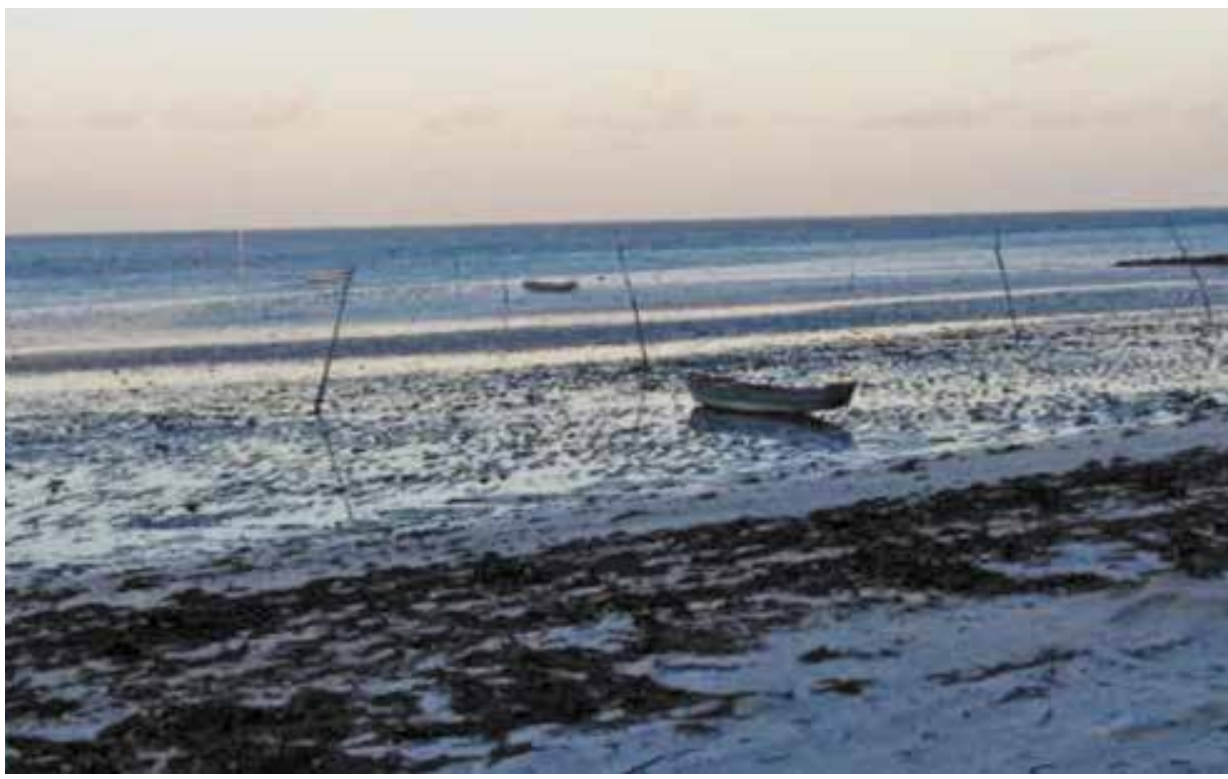

Fonte: Os autores (2016).

Figura 4: Planície de maré na área do porto da comunidade de Atapuz.

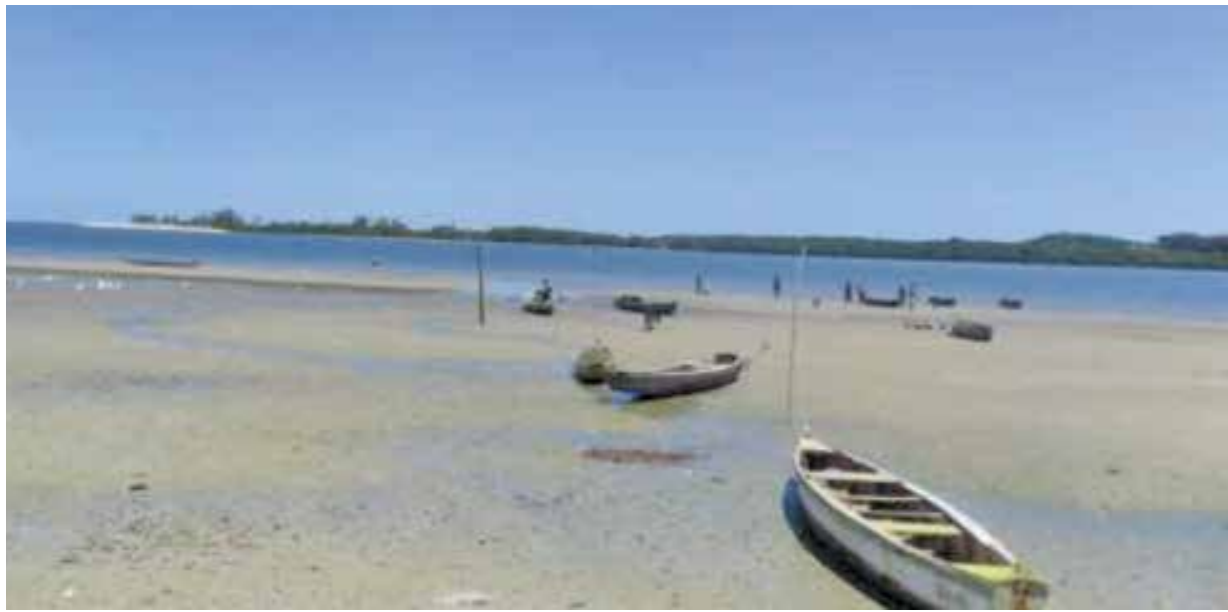

Fonte: Os autores (2016). 
Roberta Kelly Fernandes-da-Silva, Vanessa Martins-Lopes, Osvaldo Girão. Avaliação preliminar dos conhecimentos etnoclimático e etnogeomorfológico de pescadores do litoral do Município de Goiana - estado de Pernambuco / Brasil

A oscilação dessas diversas formas de marés é importante para a pesca, pois vai depender dela a decisão dos pescadores de irem pescar determinados tipos de espécies. Essa dinâmica vai determinar a ida e a volta dos pescadores, e os tipos de pescado que eles podem conseguir.

Outro fator que influencia na pesca é a dinâmica das ondas sobre a linha de costa, que se constituem um dos processos marinhos mais efetivos na modelação das áreas costeiras, pois atuam no selecionamento e redistribuição dos sedimentos depositados nas regiões costeiras e plataforma continental interna (Bird, 2008).

As ondas são impulsionadas pela ação do vento, que ao soprar exerce variação de pressão que provoca uma oscilação vertical na superfície da água, que se torna rugosa. O vento empurra essa ondulação ao mesmo tempo que cria depressão por turbulência, a sotavento de cada ondulação. Esse processo gera a configuração das ondas de gravidade. Uma vez geradas as ondas mantém sua trajetória mesmo fora da área de ação do vento, quando passam a ser denominadas de "marulho". A topografia de fundo exerce grande influência sobre as ondas alterando a sua propagação e velocidade (Muehe, 1994; Bird, 2008; Davidson-Arnott, 2010).A forma como a onda arrebenta em fronte a praia depende do gradiente do fundo marinho e geometria da onda. Depois da arrebentação a onda atravessa a zona de surfe até atingir a face da praia, onde se espraia e depois reflui.

Muitos pescadores relataram que as ondas, quando fortes, também chamadas de "cabeço" por muitos, atrapalham na hora do lance da rede, porque causa "repuxo", ou seja, quando a rede é jogada na água, a rede enrola e eles não conseguem pescar. Outros disseram que a onda pode ser boa para a pesca, porque quando elas quebram nos bancos de areia, denominados por eles de "croas", atraem os peixes.

Também percebem que as ondas vêm modificando a paisagem, criando croas, onde antes era mangue e zonas de berçário dos peixes, e mesmo causando destruição de casas e caiçaras, sendo necessária, para minimizar esse processo, a colocação de sacos de areia, fragmentos rochosos e troncos de madeira para diminuir a força da onda e mesmo acumular areia. Outros acreditam que além dessas contenções feitas para minimizar a ação do mar, existem formas naturais que também protegem a ação marinha, como: pedras de laje e arrebentações, denominações locais para arrecifes e croas. 
Roberta Kelly Fernandes-da-Silva, Vanessa Martins-Lopes, Osvaldo Girão. Preliminary evaluation of the ethnoclimatic and ethnogeomorphologic knowledge of fishermen of the coast of the Municipality of Goiana state of Pernambuco / Brazil

Com relação a dinâmica hidrológica no litoral de Goiana, a percepção que os pescadores têm em relação à diferença da água do rio para a água do mar é que a do rio é doce, limpa, mais "avermelhada" e "pesada", devido à presença de matéria orgânica nas margens e que são lançadas para o rio Mageó e o canal de Santa Cruz, e a presença de mais peixesnas desembocaduras derivada do lócus de desova que estas reprresentam.

Já a água do mar é mais suja, quente, salgada e é boa para a pesca. Também relatam a diferença do "mar de dentro" para o "mar de fora", delimitado pelo que eles chamam de canal ou pelos arrecifes. Dizem que o mar de dentro tem menos espécies, e é "manso", raso, a água é mais escura e próxima de estuários. No "mar de fora" existem corais, é "brabo" (agitado), mais fundo e perigoso, pesado e limpo.

Também frisaram a importância que o rio Megaó e o canal de Santa Cruz possuam para as comunidades e para a manutenção do meio ambiente, pois estes preservam os viveiros para que os peixes entrem, desovem, cresçam e voltem para o mar, tornando os ambientes estuarinos com maior concentração de peixes e maios variedade de espécies.

\section{As formas geomorfológicas}

Conforme a correlação das nomenclaturas observa-se que a classificação etnogeomorfológica apresenta correlações pertinentes com a classificação e conceituação geomorfológica acadêmica, levando-se em consideração os elementos altimétricos, paisagísticos, litológico, deposicional e erosivo.

O Quadro 1 apresenta uma correlação da nomenclatura etnogeomorfológica com nomenclatura geomorfológica de cunho acadêmico para os três ambientes costeiros-estuarinos aqui considerados.

A partir das entrevistas realizadas foi possível notar que a relação com elementos e processos naturais, tecida através da pesca, não se dá de forma agressiva e degradante para a dinâmica físico-natural, mas firmada no reconhecimento da importância do ambiente natural, em seus aspectos bióticos e abióticos, tanto para a manutenção da comunidade local, garantindo a sua segurança alimentar e reprodução sociocultural, como para a dinâmica paisagística, que embasa certa atividade turística recreativa atrelada aos ambientes costeiro e estuarino. 
Roberta Kelly Fernandes-da-Silva, Vanessa Martins-Lopes, Osvaldo Girão. Avaliação preliminar dos conhecimentos etnoclimático e etnogeomorfológico de pescadores do litoral do Município de Goiana - estado de Pernambuco / Brasil

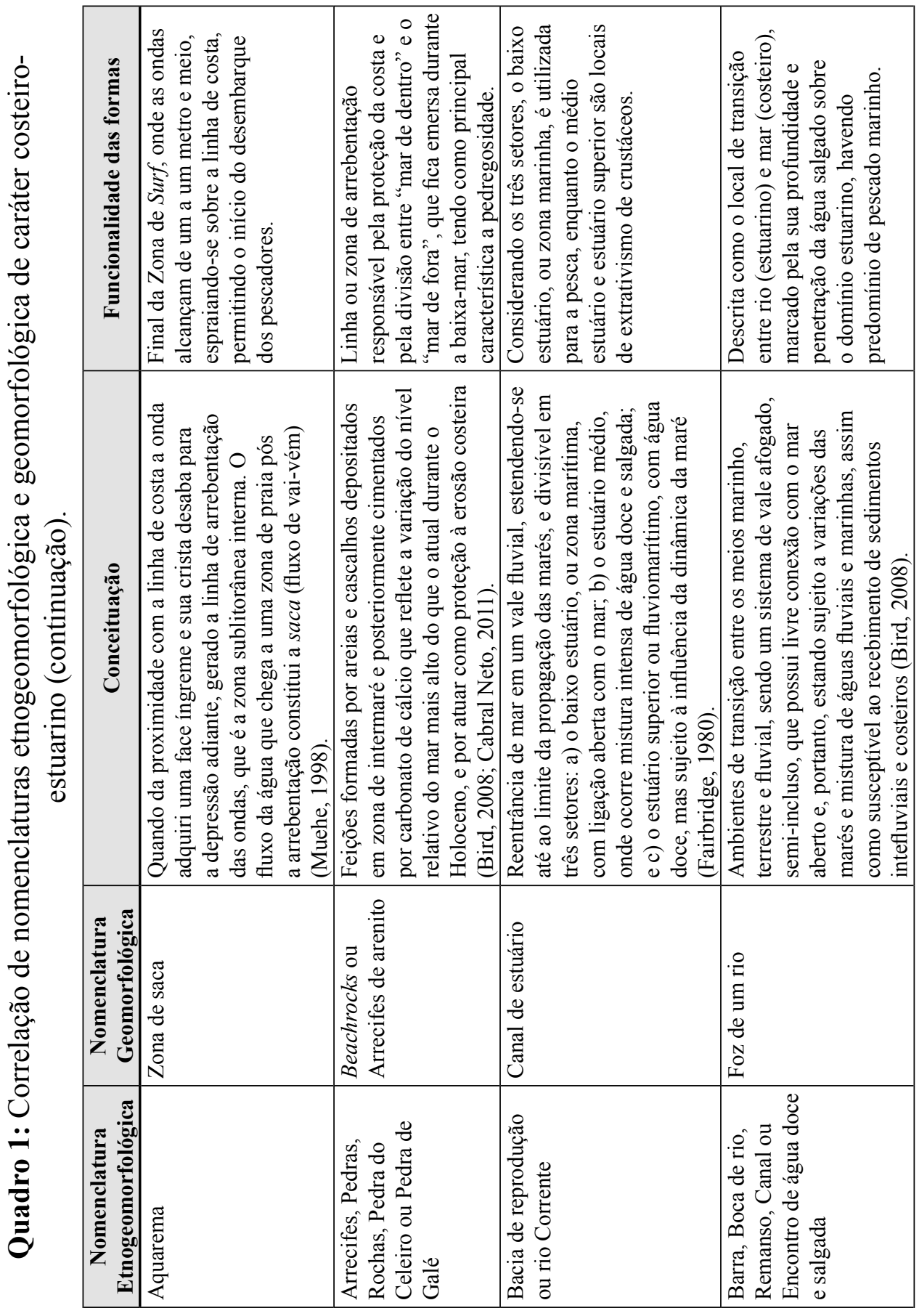


Roberta Kelly Fernandes-da-Silva, Vanessa Martins-Lopes, Osvaldo Girão. Preliminary evaluation of the ethnoclimatic and ethnogeomorphologic knowledge of fishermen of the coast of the Municipality of Goiana state of Pernambuco / Brazil

\begin{tabular}{|c|c|c|c|}
\hline 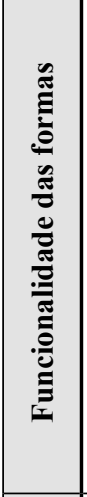 & 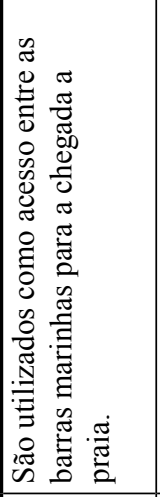 & 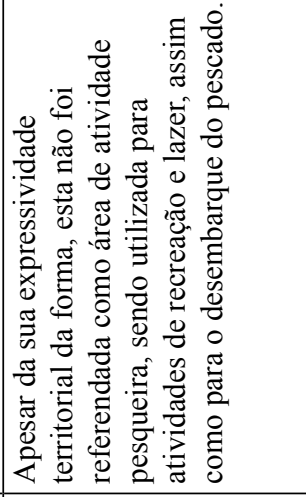 & 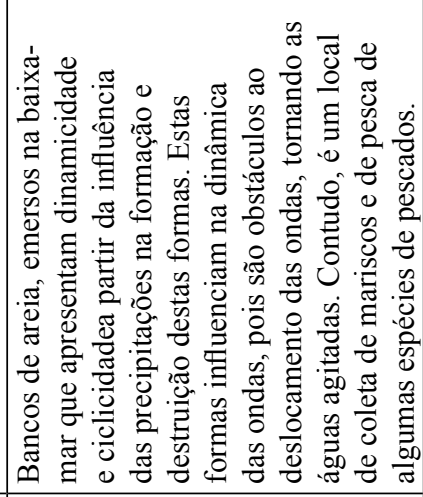 \\
\hline ن & 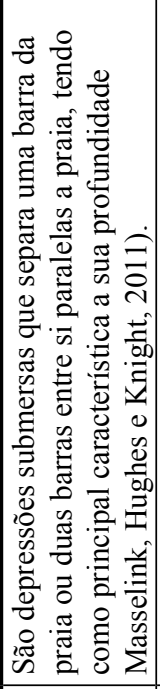 & 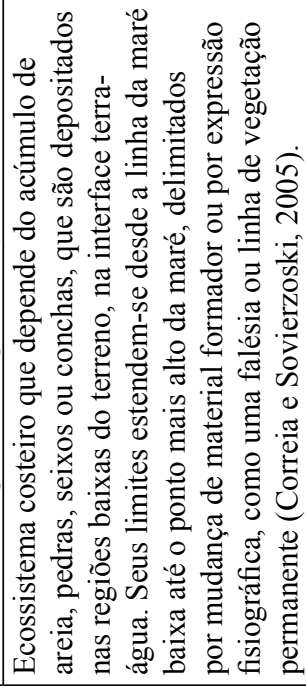 & 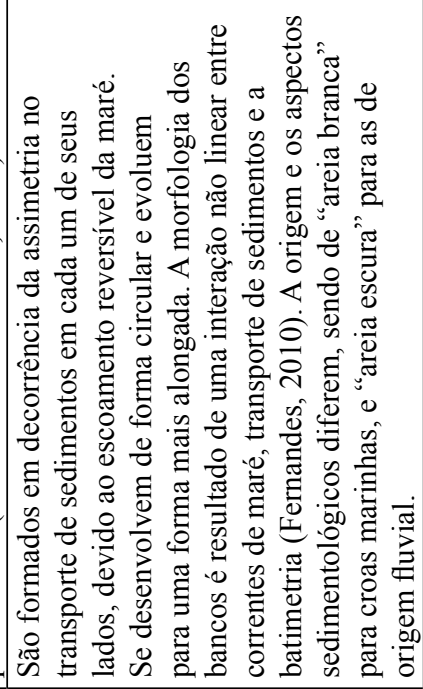 \\
\hline 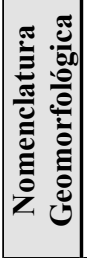 & 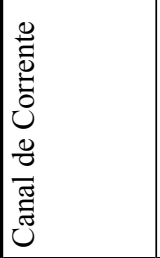 & 恋 & 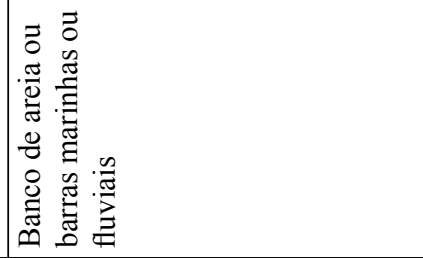 \\
\hline 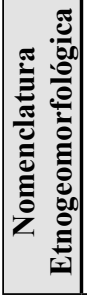 & & 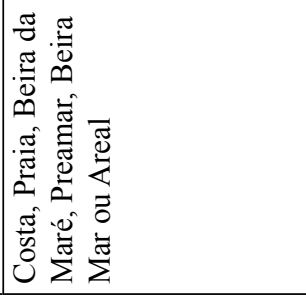 & 0 \\
\hline
\end{tabular}


Roberta Kelly Fernandes-da-Silva, Vanessa Martins-Lopes, Osvaldo Girão. Avaliação preliminar dos conhecimentos etnoclimático e etnogeomorfológico de pescadores do litoral do Município de Goiana - estado de Pernambuco / Brasil

\begin{tabular}{|c|c|c|}
\hline 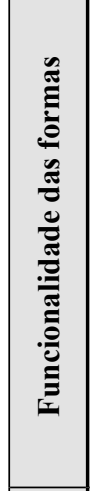 & 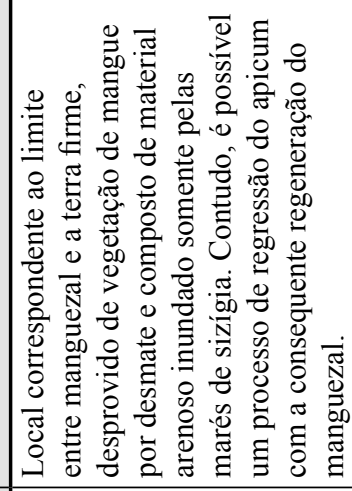 & 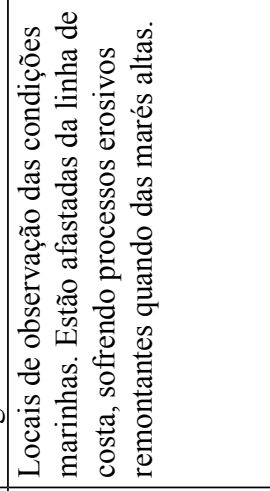 \\
\hline ن⿺辶ِّ & 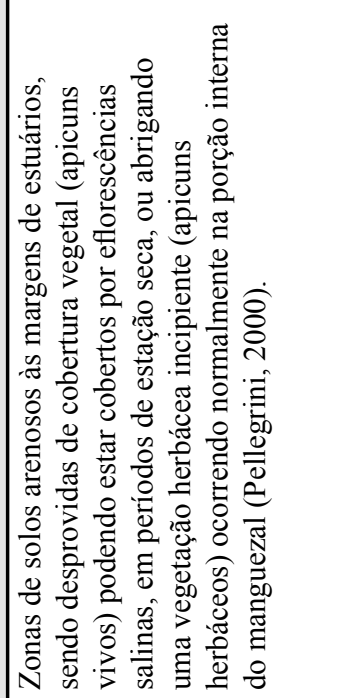 & 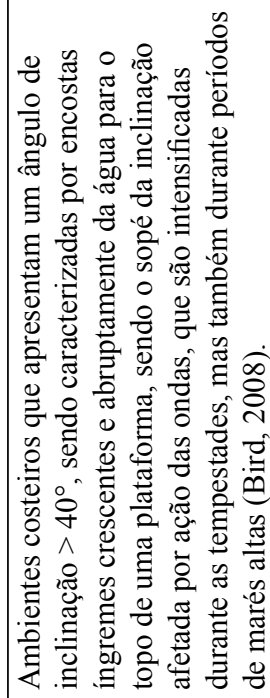 \\
\hline 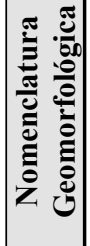 & $\begin{array}{c} \\
\vdots \\
0 \\
.0 \\
0 \\
\frac{0}{4}\end{array}$ & $\begin{array}{l}\frac{\pi}{v} \\
\frac{0}{\pi} \\
\frac{\pi}{\pi}\end{array}$ \\
\hline 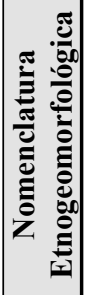 & 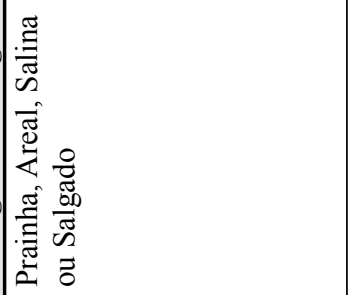 & 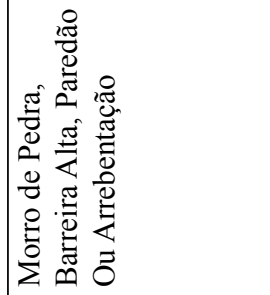 \\
\hline
\end{tabular}


Roberta Kelly Fernandes-da-Silva, Vanessa Martins-Lopes, Osvaldo Girão. Preliminary evaluation of the ethnoclimatic and ethnogeomorphologic knowledge of fishermen of the coast of the Municipality of Goiana state of Pernambuco / Brazil

O quadro de correlação de formas etnogeomorfológicas e geomorfológicas exprime entendimentos e classificações acerca de formas de relevo emersas e submersas dos ambientes costeiro e estuarino, bem como, em tópicos anteriores, sobre processos de caráter geomorfológico e hidrodinâmico atuantes em ambos.

No que concerne às formas de relevo, emersas e submersas, observou-se que os pescadores reconhecem a diversidade, a similaridade, a sazonalidade, a dinamicidade, a universalidade - no sentido de ocorrência em dimensão global - e a influência das formas sobre a pesca e os processos hidrodinâmicos locais.

Ao longo deste estudo, de caráter preliminar, constatou-se que o pescador tem a plena consciência de que a atividade humana, independentemente de sua cultura, tem dependência da natureza. Justamente por reconhecer essa importância, para Diegues (1996, Apud Alves e Nishida, 2002) essas comunidades são marcadas de maneira geral pelo respeito aos ciclos naturais e exploração dentro da capacidade de recuperação das espécies consideradas como recursos pesqueiro e/ou extrativista.

Os relatos demonstraram que a vida cotidiana do pescador artesanal está atrelada ao tempo e dinâmica da natureza do ambiente costeiro, por isso ele aprendeu a traduzí-la, construindo um rico conhecimento sobre formas, processos e as espécies que habitam as águas que fornecem matéria biótica em recursos para seu sustento, sendo este conhecimento necessário para sua reprodução social, econômica e cultural.

Ao considerar o reconhecimento do etnoconhecimento geomorfológico como forma de contribuição das populações tradicionais para ações de planejamento e gestão ambiental e territorial, vislumbra-se formas de estimular práticas coerentes com o conhecimento de formas e processos costeiros para a plena manutenção, e mesmo ampliação, das potencialidades locais relativas aos recursos naturais (Lopes, 2017).

Desta forma, compreender os conceitos e práticas desenvolvidas nos ambientes costeiros e estuarinos pelos pescadores das comunidades estudadas, assim como para o levantamento dos conhecimentos locais necessários às comunidades relativos às formas e processos costeiros e estuarinos de cunho etnogeomorfológico, embasam suas ações a partir da dinâmica do meio ambiente em que vivem. 
Roberta Kelly Fernandes-da-Silva, Vanessa Martins-Lopes, Osvaldo Girão. Avaliação preliminar dos conhecimentos etnoclimático e etnogeomorfológico de pescadores do litoral do Município de Goiana - estado de Pernambuco / Brasil

O conhecimento etnogeomorfológico dos pescadores é diverso, amplo e coerente, pois aprendendo e apreendendo acerca dos elementos e processos físicos os pescadores se apropriam da natureza e constroem seus saberes. Assim sendo, como tantas outras comunidades tradicionais, o conhecimento dos pescadores artesanais é um recurso valioso e consistente o suficiente para ser considerado nos planos de desenvolvimento e em estudos de manejo de meio ambiente local.

Assim, aetnogeomorfologia, enquanto uma abordagem acadêmica, pode contribuir não somente à geomorfologia, mas a outras ciências ambientais ao contribuir com conhecimento da relação de comunidades com o ambiente natural em que habitam, podendo propiciar a adequabilidade e melhor execução de projetos ambientais e de ordenamento territorial de intervenção local, que levem em consideração não somente a dinâmica geomorfológica e ecológica, mas também os valores, conhecimentos e práticas socioculturais locais correlacionadas com estes campos de conhecimento, mas com uma visão de caráter etno, pois a necessária participação dos povos locais para buscar uma maior visibilidade e estabelecer ações e práticas de gestão de desenvolvimento cultural, econômico e socioambiental junto ao Estado e demais parcerias de caráter não-governamentais, possibilita o pensar e agir apartir de uma perspectiva de conhecimentos locais que podem ampliar as potencialidades locais relativas aos recursos naturais atreladas aos recursos culturais.

\section{Agradecimentos}

Os autores agradecem ao Programa Institucional de Bolsas de Iniciação Científica (PIBIC/UFPE/CNPq - Edital 2015-2016) pelo apoio relativo à disponibilidade de bolsa-PIBIC para a primeira autora.

\section{Referencias}

Alves, R. R. N. \& Nishida, A. K. (2002). A Ecdise do Caranguejo-Uçá, UcidesCordatus L. (Decapoda, Brachyura) na visão dos caranguejeiros. In: Interciência, 27(3), 110-117.

Bird, E. (2008).Coastal geomorphology: An introduction. Chichester, West Sussex, Inglaterra: John Wiley \& Sons Ltd.

Cabral, C. J., Silva, W. F. \& Girão, O. (2013). Impactos ambientais derivados do uso e ocupação da linha de costa em trechos das praias de 
Roberta Kelly Fernandes-da-Silva, Vanessa Martins-Lopes, Osvaldo Girão. Preliminary evaluation of the ethnoclimatic and ethnogeomorphologic knowledge of fishermen of the coast of the Municipality of Goiana state of Pernambuco / Brazil

Pau Amarelo e Maria Farinha - município de Paulista/PE: Estudo preliminar. In: Revista da Casa da Geografia de Sobral (RCGS), Sobral-CE, 16(1), 74-88.

Cabral-Neto, I. (2011). Beachrocks do Rio Grande do Norte: Correlação entre os depósitos costeiros e os de zona costa-afora com base na faciologia, petrografia e diagênese. Dissertação de Mestrado. Centro de Ciências Exatas e da Terra, Universidade Federal do Rio Grande do Norte. Brasil. (pp.145).

Correia, M. D. \& Sovierzoski, H.H. (2005). Ecossistemas marinhos: Recifes, praias e manguezais. Maceió, Brasil: EDUFAL - Série Conversando sobre ciências em Alagoas.

Carvalho-Neta, M. L., Ribeiro, S. C., Marcal, M. S. \& Lima, G.G. (2014). Mapeamento Etnogeomorfológico do Distrito de Arajara, Barbalha/ CE. In: Revista Geonorte, 4, 208-212.

Companhia Pernambucana DO Meio Ambiente-CPRH. (2003). Diagnóstico socioambiental do Litoral Norte de Pernambuco. Recife, Brasil: CPRH. (pp. 214).

Davidson-Arnott, R. (2010). An Introduction to Coastal Processes and Geomorphology. New York, Estados Unidos: Cambridge University Press.

Diegues, A. C. S. (1996). O mito moderno da natureza intocada. São Paulo, Brasil: HUCITEC.

Fairbridge, R. W. (1980). "The Estuary: Its definition and geodynamic cycle". Chemistry and Biogeochemistry of Estuaries. Nova Yorque, EstadosUnidos: John Wiley and Sons. (pp. 1-35).

Fernandes, R. D. (2010). Formação e evolução dos bancos de areia na foz do rio Amazonas. Tesede Doutorado. COPPE, Universidade Federal do Rio de Janeiro. Brasil. (pp. 113).

Folhes, M. T. E. \& Donald, N. (2007). Previsões tradicionais de tempo e clima no Ceará: O conhecimento popular a serviço da ciência. In: Sociedade e Natureza, 19(2), 19-31.

Fuentes, M. C., Bastos, S. B. \& Santos, N. M. (2015). Estudo do conhecimento climático popular na região semiárida do estado da Bahia. In: Revista de Ciências Humanas-Viçosa, 15(2), 349-365.

Gascón, M. (2014). Etnoclimatologia en la Araucanía y las Pampas. Clima y relaciones interétnicas entre los siglos XVI y XIX. In: Dimensión Antropológica, 60, 37-60. 
Gascón, M. \& Caviedes, C. (2014). Etnoclimatologia en las Pampas: el remonte térmico en la frontera Sur. In: TEFROS, 12(2), 140- 154.

Laraia, R. B. (2009). Cultura: Um conceito antropológico. 23 ed. Rio de Janeiro, Brasil: Jorge Zahar Ed.

Lopes, V. M., Pereira, C. E. G. (2014). O homem, o relevo e a cultura: etnogeomorfologia sertaneja na região sul do Ceará-Brasil. In: Anais do Congreso Iberoamericano de Estudios Territoriales Y Ambientales, São Paulo, Brasil (pp. 3164- 3181).

Lopes, V. M. (2017). Etnogeomorfologia costeira e estuarina em comunidades de pescadores artesanais do litoral de Goiana, Pernambuco. Dissertação de Mestrado. Departamento de Ciências Geográficas, Programa de Pós-Graduação em Geografia, Universidade Federal de Pernambuco. Brasil. (pp. 188).

Manso, V. A. V., Coutinho, P. N., Guerra, N. C., \& Junior, C. F. A. S. (2006). "Erosão e Progradação do Litoral Brasileiro/Pernambuco". Erosão e Progradação do Litoral Brasileiro. Brasília, Brasil: Ministério do Meio Ambientes. (pp.179-196).

MAsselink, G, Hugues, M. G. \& Knight, J. (2011). Coastal Processes \& Geomorphology. 2 ed. London, Inglaterra: Hodder Education.

Medeiros, N., Pinto, A. \& Rozendo, C. (2014). Profetas da chuva do Seridó Potiguar, Brasil. In: Boletim do Museu Paraense Emílio Goeldi - Ciências Humanas, 9(3), 773-795.

Muehe, D. (1994). "Geomorfologia Costeira". Geomorfologia: Uma atualização de bases e conceitos. Rio de Janeiro, Brasil: Bertrand Brasil. (pp.253-308).

Muehe, D. (2006). Erosão e progradação no litoral brasileiro. Brasília, Brasil: Ministério do Meio Ambiente.

Nasuti, S., Curi, M., Medeiros, N., Pinto, A., Ibiapina, I., Rozendo, C. \& Hiroo, C. (2013). Conhecimento tradicional e previsões meteorológicas: Agricultores familiares e as "experiências de inverno" no Semiárido Potiguar. In: Revista econômica do Nordeste, 44, $\mathrm{n}^{\circ}$ especial, 383-402.

Oliveira, L. T. (2003). Aspectos Hidrogeológicos da Região Costeira Norte de Pernambuco (Paulista a Goiana). Dissertação de Mestrado. Centro de Tecnologia e Geociências, Universidade Federal de Pernambuco, Recife. Brasil. (pp. 119). 
Pellegrini, J. A.C. (2000). Caracterização da planície hipersalina (Apicum) associada a um bosque de mangue em Graratiba, Baía de Sepetiba, Rio de Janeiro-RJ. Dissertação de Mestrado.Instituto Oceanográfico, Universidade Federal de São Paulo. Brasil. (pp. 101).

RIbeiro, S. C. (2012). Etnogeomorfologia sertaneja: Proposta metodológica para a classificação das paisagens da sub-bacia do rio Salgado/ CE. Tese de Doutorado.Centro de Ciências Matemáticas e da Natureza, Universidade Federal do Rio de Janeiro. Brasil. (pp. 278).

Silva, F. A. N. (2012). Análise do comportamento sedimentológico e hidrodinâmico da desembocadura norte do Canal de Santa Cruz-PE. Dissertação de Mestrado. Centro de Tecnologia e Geociências, Universidade Federal de Pernambuco, Recife. Brasil. (pp. 115).

Sotchava, V. B. (1977). O estudo de geossistemas. Tradução de Carlos Augusto Figueiredo Monteiro e Dora de Amarante Romariz. São Paulo: Universidade de São Paulo - Instituto de Geografia.

Toledo, V. M. \& Barrera-Bassols, N. A. (2009). Etnoecologia: uma ciência pós-normal queestuda as sabedorias tradicionais. In: Desenvolvimento e Meio Ambiente, 20, 31-45. 